\title{
IMPLEMENTASI AUTOMATIC TRANSFER SWITCH BERBASIS PLC PADA LABORATORIUM TEKNIK ELEKTRONIKA JURUSAN TEKNIK ELEKTRO UNIVERSITAS LAMPUNG
}

\author{
Hendro Utomo ${ }^{1}$, Ageng Sadnowo ${ }^{2}$, Sri Ratna $S^{3}$ \\ 1,2,3 Jurusan Teknik Elektro Universitas Lampung \\ Jl. Prof. Sumantri Brojonegoro No.1 Bandar Lampung 35145 \\ 'askhendroutomo@gmail.com, ${ }^{2}$ ageng@unila.ac.id, ${ }^{3}$ sriratnasulistiyanti@gmail.com
}

\begin{abstract}
Abstrak
Laboratorium Elektronika Jurusan Teknik Elektro Universitas Lampung merupakan tempat bagi para mahasiswa dalam melakukan studi, praktikum maupun penelitian dengan listrik sebagai kebutuhan utamanya. Tanpa listrik, kegiatan-kegiatan tersebut akan terhenti.

Sebagaimana diketahui, listrik di Indonesia dilayani oleh Perusahaan Listrik Indonesia yang merupakan satu-satunya perusahaan terbesar yang menyediakan listrik untuk Indonesia. Sehingga ketika terjadi pemadaman akibat adanya perawatan, tidak ada suplai daya cadangan yang dapat melayani. Kalaupun ada, itu berupa genset yang melayani listrik secara terbatas. Selain itu perlu peran manusia dalam mengoperasikannya. Pengoperasian oleh manusia memiliki banyak kelemahan. Untuk itu, perlu adanya sebuah alat atau mekanisme yang dapat menggantikan kerja yang dilakukan secara manual oleh manusia menjadi otomatis.
\end{abstract}

Automatic Transfer Switch (ATS) merupakan salah satu solusi pemecahan masalah ini. ATS ini akan menggantikan peran operator genset yang harus siaga saat terjadi pemadaman pada sumber utama listrik yaitu PLN. Pekerjaan yang digantikan oleh ATS dari operator di antaranya menyalakan genset saat terjadi pemadaman (starting genset), memantau kondisi operasi genset hingga normal dan siap menyuplai daya, memindahkan saklar beban utama dari sumber listrik PLN ke genset maupun sebaliknya serta mematikan genset saat sumber listrik PLN sudah kembali menyuplai daya.

Kata kunci : Genset, PLN, Beban, ATS

\section{Abstract}

An Electronica's Laboratory in Electrical Engineering University of Lampung is a place for students to study, practice and making some reasearch with an electricity power as the main requirment. Without electricity power, anyother activity will be stopped.

As we know, Indonesian electricity supplied by Perusahaan Listrik Negara as the only one the largest electricity company in Indonesia. Then, when it stopping the services, there is no one can supplied back up electricity. Moreover, local generator can give the eletricity but it's limited. But, when it's running also need to controlling. So, we need some tools or mechanism that changing human work from manual to automatic.

Automatic Transfer Switch (ATS) is one of the solution in this case. ATS can changing human work as a genset operator that have to standbye when electricity down from the main source, thats PLN. Some work should handled by ATS such as get local generator running when electricity was down (genset setarting), monitoring local generator till it's get normally running and ready to supply the electricity, changing the main switch of load from PLN electricity source to localy generator or return and also get local generator running off when PLN come to supplied the electricity back.

Keyword: local generator, PLN, load, ATS. 


\section{PENDAHULUAN}

Laboratorium Teknik Elektronika merupakan salah satu Laboratorium yang ada di Jurusan Teknik Elektro. Dalam aktivitas sehari-hari, laboratorium ini sering dipakai untuk praktikum dan mengerjakan penelitian. Untuk keperluan tersebut, dibutuhkan suplai daya listrik yang stabil dan terus-menerus. Jika listrik tidak ada, maka kegiatan tersebut akan tertunda sehingga kegiatan tersebut tidak selesai sesuai dengan jadwal yang telah ditentukan.

Perusahaan Listrik Negara (PLN) merupakan satu-satunya perusahaan yang menyediakan listrik di Indonesia. Hal ini membawa sisi positif maupun negatif. Diantaranya PLN dapat memberikan pelayanan listrik yang terbaik dengan harga yang terjangkau. Akan tetapi ketika pihak PLN akan melakukan perawatan yang harus memadamkan listrik maka tidak ada sumber listrik lain yang dapat menjadi cadangan. Satu-satunya yang dapat dilakukan oleh pengguna listrik PLN adalah dengan menyediakan sumber listrik mandiri atau yang biasa disebut dengan Generator Set atau Genset.

Adanya generator set dapat membantu mengatasi permasalahan kelistrikan ketika terjadi pemadaman. Dengan adanya genset maka aktivitas sehari-hari di perkantoran pun dapat terlaksana meskipun suplai listrik utama dari PLN tidak ada.

Akan tetapi, adanya genset pun belum sepenuhnya menyelesaikan masalah. Karena dibutuhkan operator khusus yang mengerti pengoperasian genset. Selain itu, operator jugalah yang mengetahui letak genset dan letak saklar pemindah beban. Sehingga listrik dari dapat terdistribusi ke jaringan listrik yang membutuhkan.

Adapun keberadaan operator tidak selalu siaga saat terjadi pemadaman. Hal ini menjadi permasalahan tersendiri dalam mengoperasikan genset. Selain itu, dibutuhkan kecepatan dalam menyalakan genset saat PLN secara tiba-tiba melakukan pemadaman agar tidak terjadi kepanikan pada pengguna listrik yang memiliki genset.

Untuk itulah mucul sebuah ide perancangan dan implementasi Automatic Transfer Switch (ATS) yang merupakan salah satu solusi dalam memecahkan masalah ini. ATS ini akan menggantikan peran operator genset yang harus selalu siaga saat terjadi pemadaman oleh PLN.

\section{TINJAUAN PUSTAKA}

\subsection{Automatic Transfer Switch (ATS)}

Automatic Transfer Switch (ATS) adalah suatu rangkaian yang mampu memindahkan beban dari sumber listrik utama ke sumber listrik cadangan. ATS terdiri dari beberapa sakelar yang menyerupai home sakelar, hanya saja perangkat ATS ini sudah mampu bekerja secara otomatis.

Sistem pengoperasian perangkat ATS ini sangatlah muda, karena panel terinstalasi dengan baik sehingga ketika daya utama misalnya PLN hilang atau gagal, maka perangkat ATS ini akan segera memindahkan beban dari PLN ke genset. Begitu pula sebaliknya, ketika PLN kembali menyuplai daya maka ATS akan segera memindahkan beban dan mematikan genset.

Komponen-komponen penyusun ATS meliputi lampu indikator, kontaktor dan relay-relay. Kontaktor berjumlah dua unit yaitu satu unit untuk kontaktor genset dan satu unit yang lain untuk kontaktor PLN. Prinsip dari kontaktor ini adalah ketika salah satu kontaktor bekerja, maka kontaktor yang lain akan terkunci atau interlock. Sehingga hanya satu suplai daya yang dapat terhubung ke beban serta menghindari terhubungnya suplai daya utama dengan suplai daya cadangan. [3]

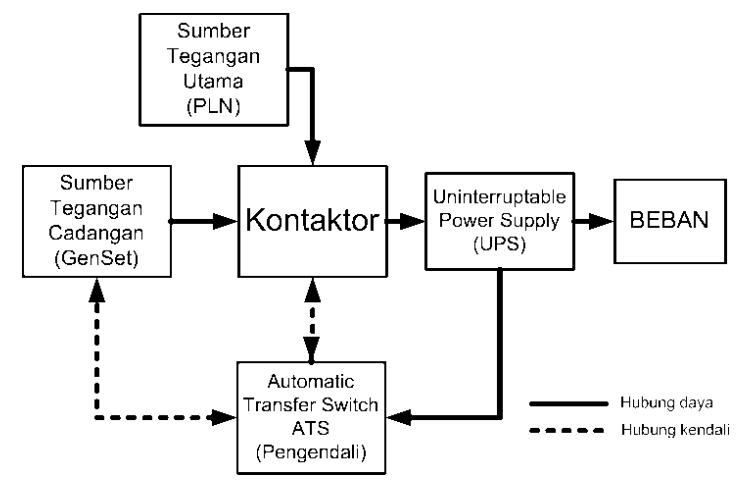

Gambar 1. Blok diagram Automatic Transfer Switch.

\subsection{Programmable Logic Controller (PLC)}

Secara hitoris, PLC pertama kali dirancang perusahaan General Motor (GM) sekitar tahun 1968 untuk menggantikan control relay pada proses sekuensial yang dirasakan tidak fleksibel dan berbiaya tinggi. Pada saat itu, hasil rancangan telah benar - benar berbasis 
komponen solid state dan memiliki fleksibilitas tinggi, hanya secara fungsional masih terbatas pada fungsi-fungsi kontrol saja.

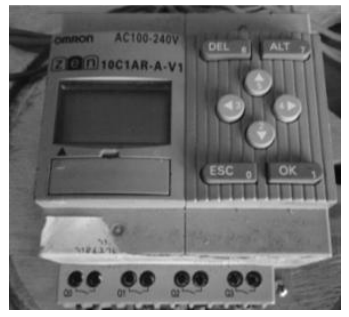

Gambar 2. Programmable Logic Controller.

\section{A. Prinsip kerja PLC}

Prinsip kerja dari sebuah PLC yaitu menerima data-data berupa sinyal dari external input device pada sistem yang dikontrol. Prinsip kerja PLC ditunjukkan oleh gambar di bawah ini.

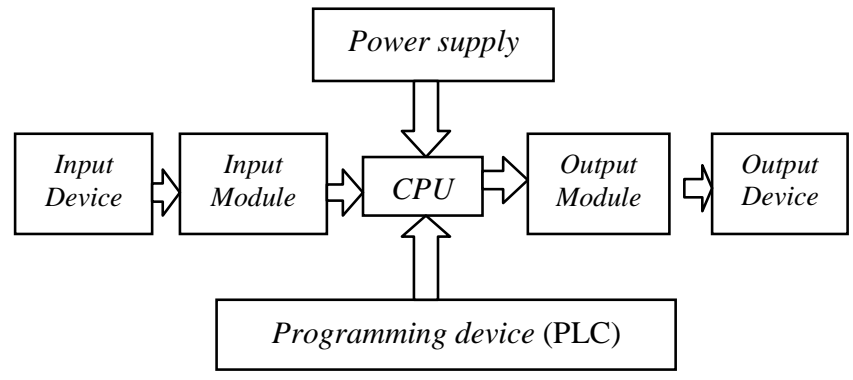

Gambar 3. diagram blok sistem PLC.

Peralatan input luar tersebut antara lain berupa sakelar, tombol atau sensor. Data-data masukan yang masih berupa sinyal analog akan diubah oleh modul input A/D (Analog to Digital input module) menjadi sinyal digital. Selanjutnya oleh prosesor pusat (CPU) yang ada di dalam PLC, sinyal digital itu dioleh sesuai dengan program yang telah dibuat dan disimpan di dalam memori. Kemudian CPU mengambil keputusan dan memberikan perintah melalui output dalam bentuk sinyal digital. Modul output D/A (Digital to Analog module) dari sistem yang dikendalikan, di antaranya kontaktor, relay, solenoid, alarm, dimana nantinya dapat mengoperasikan sistem proses yang dikendalikan tersebut secara otomatis.

\section{B. Diagram Ladder}

Diagram ladder (tangga) adalah skema penyajian proses kontrol sekuensial. Dalam penggambaran diagram tangga dikenal simbol-simbol sebagai berikut :

\section{a. Saklar Normally Open}

Saklar ini menandakan keadaan saklar yang normalnya pada posisi off (terbuka), dan akan On (terhubung) bila relay telah terenergize. Simbol NO ditunjukkan pada gambar di bawah ini.

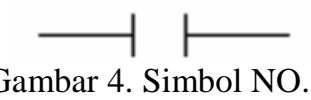

Pada gambar di atas, jika saklar ter-energize, maka kontaktor akan berubah kondisi menjadi tertutup.

\section{b. Saklar Normally Close}

Saklar ini menandakan keadaan saklar yang normal pada keadaan On (terhubung), jadi jika saklar tersebut diaktihkan akan menjadi Off (terbuka). Simbol NC ditunjukkan pada gambar di bawah ini.

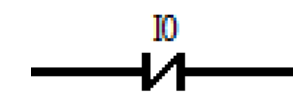

Gambar 5. Simbol NC.

Pada gambar di atas, saat saklar ter-energize, maka kontaktor akan berubah kondisi menjadi terbuka.

\section{c. Keluaran}

Keluaran relay akan mengakatifkan kontakkontak NO dan NC. Simbol dari keluaran ini ditunjukkan oleh gambar di bawah ini.

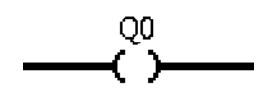

Gambar 6. Keluaran relay.

Keluaran akan aktif jika ada perubahan pada input keluaran tersebut.

Komponen pada PLC

Komponen pada PLC terdiri dari latch, timer, counter dan MCR. Komponen tersebut memiliki fungsi yang berbeda. Komponen latch berfungsi sebagai penahan, timer berfungsi sebagai menunda waktu, counter berfungsi sebagai pencacah, dan MCR berfungsi sebagai pengontrol program. 


\section{Komponen Latck (pengunci)}

Komponen ini berfungsi menahan keluaran untuk masukan sesaat. Ada dua jenis fungsi yang berkaitan dengan komponen ini,

SET : menahan keluaran untuk status ON (latch) RST : menahan keluaran untuk status OFF (unlatch)

\section{Komponen timer}

Ada tiga macam komponen timer yaitu :

TON : ON delay timer, yaitu menunda waktu hidup selama selang waktu tertentu.

TON : OFF delay timer, yaitu menunda waktu hidup selama selang waktu tertentu.

TMR : integerating timer, yaitu menunda waktu hidup selama selang integral waktu tertentu.

\section{Komponen counter}

Beberapa fungsi yang berkaitan dengan counter di antaranya :

CTU : Up counter, yaitu nilai counter akan dinaikkan untuk setiap pulsa yang masuk dan kontaktor akan berubah kondisinya jika pulsa yang masuk telah sama dengan nilai setting pada counter tersebut.

CTD : Down counter, yaitu kebalikan dari CTU, nilai counter akan diturunkan, kontaktor akan berubah kondisi jika pulsa yang masuk telah sama dengan nilai setting pada counter tersebut.

CTUD : Up/Down counter, yaitu gabungan dari CTU dan CTD serta reset. [6]

\subsection{Kelas Meter}

Untuk mendapatkan hasil pengukuran yang mendekati dengan harga sebenarnya, perlu memperhatikan batas kesalahan yang tertera pada alat ukur tersebut. Klasifikasi alat ukur listrik menurut Standar IEC no. 13B-23 menspesifikasikan bahwa ketelitian alat ukur dibagi menjadi 8 kelas, yaitu : 0,$05 ; 0,1 ; 0,2$; 0,$5 ; 1,0 ; 1,5 ; 2,5 ;$ dan 5 .

Kelas-kelas tersebut artinya bahwa besarnya kesalalahan dari alat ukur pada batas-batas ukur masing-masing kali $\pm 0,05 \%, \pm 0,1 \%, \pm 0,2 \%$, $\pm 0,5 \%, \pm 1,0 \%, \pm 1,5 \%, \pm 2,5 \%, \pm 5 \%$ dari relatif harga maksimum.

Dari 8 kelas alat ukur tersebut digolongkan menjadi 4 golongan sesuai dengan daerah pemakaiannya, yaitu :
(1) Golongan dari kelas 0,05, 0,1, 0,2 termasuk alat ukur presisi yang tertinggi. Biasa digunakan di laboratorium yang standar.

(2) Golongan alat ukur dari kelas 0,5 mempunyai ketelitian dan presisi tingkat berikutnya dari kelas 0,2 alat ukur ini biasa digunakan untuk pengukuran-pengukuran presisi. Alat ukur ini biasanya portebel.

(3) Golongan dari kelas 1,0 mempunyai ketelitian dan presisi pada tingkat lebih rendah dari alat ukur kelas 0,5. Alat ini biasa digunakan pada alat ukur portebel yang kecil atau alat-alat ukur pada panel.

(4) Golongan dari kelas 1,5, 2,5 dan 5 alat ukur ini dipergunakan pada panel-panel yang tidak begitu memperhatikan presisi dan ketelitian. [4]

\section{METODE PENELITIAN}

\subsection{Prosedur Penelitian}

Perancangan Automatic Transfer Switch ini diharapkan mampu mengatasi beberapa kondisi. Kondisi tersebut meliputi :

Tabel 1. Kondisi dan aktivitas yang diharapkan dalam ATS.

\begin{tabular}{|c|c|c|}
\hline \multicolumn{2}{|l|}{ Kondisi } & \multirow[b]{2}{*}{$\begin{array}{l}\text { Aktivitas } \\
\text { UPS mendapat suplai daya } \\
\text { dari PLN. } \\
\text { Beban mendapat suplai } \\
\text { daya dari UPS }\end{array}$} \\
\hline Normal & 1. Saat PLN on & \\
\hline \multirow[t]{5}{*}{ Gangguan } & $\begin{array}{l}\text { 2. Saat PLN off, genset on tapi } \\
\text { belum menyala }\end{array}$ & $\begin{array}{l}\text { Beban mendapat suplai } \\
\text { daya dari UPS. } \\
\text { UPS masih terhubung } \\
\text { dengan PLN }\end{array}$ \\
\hline & $\begin{array}{l}\text { 3. } 5 \text { detik setelah PLN off, } \\
\text { electric starter on }\end{array}$ & $\begin{array}{l}\text { Beban mendapat suplai } \\
\text { daya dari UPS. } \\
\text { UPS masih terhubung } \\
\text { dengan PLN }\end{array}$ \\
\hline & $\begin{array}{l}\text { 4. PLN off, genset on, electric } \\
\text { starter off }\end{array}$ & $\begin{array}{l}\text { Beban mendapat suplai } \\
\text { daya dari UPS. } \\
\text { UPS masih terhubung } \\
\text { dengan PLN }\end{array}$ \\
\hline & $\begin{array}{l}\text { 5. PLN off, } 60 \text { detik setelah } \\
\text { genset on }\end{array}$ & $\begin{array}{l}\text { Beban mendapat suplai } \\
\text { daya dari UPS. } \\
\text { UPS masih terhubung } \\
\text { dengan genset }\end{array}$ \\
\hline & 6. Saat PLN on, genset on & $\begin{array}{l}\text { Beban mendapat suplai } \\
\text { daya dari UPS. } \\
\text { UPS masih terhubung } \\
\text { dengan genset }\end{array}$ \\
\hline \multirow[t]{2}{*}{ Normal } & $\begin{array}{l}\text { 7. } 15 \text { detik setelah PLN on, } \\
\text { genset on }\end{array}$ & $\begin{array}{l}\text { Beban mendapat suplai } \\
\text { daya dari UPS. } \\
\text { UPS masih terhubung } \\
\text { dengan PLN }\end{array}$ \\
\hline & $\begin{array}{l}\text { 8. } 30 \text { detik setelah PLN on, } \\
\text { genset off }\end{array}$ & $\begin{array}{l}\text { Beban mendapat suplai } \\
\text { daya dari UPS. } \\
\text { UPS masih terhubung } \\
\text { dengan PLN }\end{array}$ \\
\hline & operasionalnya, & sistem \\
\hline
\end{tabular}
mengendalikan beberapa komponen. Komponenkomponen tersebut meliputi on genset, electric starter genset dan transfer switch. Operasional 
dari masing-masing komponen dijelaskan pada tabel di bawah ini.

Tabel 2. Tabel kondisi ATS rancangan.

\begin{tabular}{|c|c|c|c|c|}
\hline \multirow[t]{2}{*}{ PLN } & \multicolumn{2}{|c|}{ Genset } & \multirow{2}{*}{$\begin{array}{l}\text { Transfer } \\
\text { Switch }\end{array}$} & \multirow[t]{2}{*}{ Keterangan } \\
\hline & On & $\begin{array}{l}\text { Me- } \\
\text { nyala }\end{array}$ & & \\
\hline 1 & 0 & 0 & 0 & $\begin{array}{l}\text { UPS mendapat suplai daya dari } \\
\text { PLN }\end{array}$ \\
\hline 0 & 1 & 0 & 0 & $\begin{array}{l}0-5 \text { detik setelah PLN off, } \\
\text { Beban mendapat suplai daya dari } \\
\text { UPS } \\
\text { UPS tidak mendapat suplai daya } \\
\text { dari PLN }\end{array}$ \\
\hline 0 & 1 & 1 & 0 & $\begin{array}{l}\text { 5-8 detik setelah PLN off, } \\
\text { Beban mendapat suplai daya dari } \\
\text { UPS } \\
\text { UPS tidak mendapat suplai daya } \\
\text { dari PLN }\end{array}$ \\
\hline 0 & 1 & 1 & 1 & $\begin{array}{l}60 \text { detik setelah Genset on } \\
\text { Beban mendapat suplai daya dari } \\
\text { UPS } \\
\text { UPS mendapat suplai daya dari } \\
\text { Genset }\end{array}$ \\
\hline 1 & 1 & 1 & 1 & $\begin{array}{l}\text { Sesaat setelah PLN on kembali } \\
\text { Beban mendapat suplai daya dari } \\
\text { UPS } \\
\text { UPS mendapat suplai daya dari } \\
\text { Genset }\end{array}$ \\
\hline 1 & 1 & 1 & 0 & $\begin{array}{l}15 \text { detik setelah PLN on kembali } \\
\text { Beban mendapat suplai daya dari } \\
\text { UPS } \\
\text { UPS mendapat suplai daya dari } \\
\text { PLN }\end{array}$ \\
\hline 1 & 0 & 0 & 0 & $\begin{array}{l}30 \text { detik setelah PLN on kembali } \\
\text { Beban mendapat suplai daya dari } \\
\text { UPS } \\
\text { UPS mendapat suplai daya dari } \\
\text { PLN } \\
\text { Genset dimatikan }\end{array}$ \\
\hline
\end{tabular}

Kebutuhan dari sistem Automatic Transfer Switch ini meliputi :

\section{a. PLC (Programmable Logic Controller)}

Bagian utama dari sistem ATS ini adalah PLC. PLC berperan sebagai pengendali dari hampir semua bagian sistem ATS ini. Spesifikasi dari PLC yang digunakan dalam penelitian ini adalah :

Tabel 3. Spesifikasi PLC.

\begin{tabular}{|l|l|}
\hline Spesifikasi & Keterangan \\
\hline Tipe PLC & Omron-ZEN-10C1AR-A-V1 \\
\hline Power supply & 100 s.d 240 VAC, 50/60 Hz \\
\hline Masukan & 100 s.d 240 VAC, 6 masukan \\
\hline Luaran & Relay, 4 luaran \\
\hline Kalender dan fungsi detak & Ya \\
\hline LCD dan tombol & Ya \\
\hline
\end{tabular}

\section{b. Generator Set}

Generator Set yang dipilih menggunakan electric starter agar ketika Generator Set hendak dinyalakan, tidak perlu penanganan oleh operator. Atau dengan kata lain, peran ini telah dapat digantikan oleh PLC. Yaitu dengan memicu electric starter pada Generator Set sehingga Generator Set dapat segera menyala dan menyuplai daya ke beban.
Tabel 4. Spesifikasi genset.

\begin{tabular}{|l|l|l|}
\hline \multicolumn{2}{|l|}{ Spesifikasi } & Keterangan \\
\hline Merk & Tiger red \\
\hline Tipe & GFH8 8000LX \\
\hline AC out & Daya rerata & $5,5 \mathrm{KVA}$ \\
\cline { 2 - 3 } & Daya maksimal & $6,0 \mathrm{KVA}$ \\
\cline { 2 - 3 } & Tegangan rerata & $220 \mathrm{~V}$ \\
\cline { 2 - 3 } & Frekuensi rerata & $50 \mathrm{~Hz}$ \\
\cline { 2 - 3 } & Faktor daya & 1 \\
\hline DC out & Tegangan & $12 \mathrm{~V}$ \\
\cline { 2 - 3 } & Arus & $8,3 \mathrm{~A}$ \\
\hline
\end{tabular}

c. Kontaktor \& Relay

Perpindahan beban dari penyuplai daya utama yaitu PLN dapat dilakukan secara manual ataupun elektris. Jika secara manual, dapat menggunakan tuas beban yang dioperasikan secara manual. Sedangkan jika menginginkan perpindahan secara elektris maka kita dapat menggunakan kontaktor. Kontaktor ini mampu memindahkan beban dengan dipicu oleh tegangan dari luar yang relative lebih kecil dari daya atau tegangan pada beban.

\subsection{Diagram Alir Penelitian}

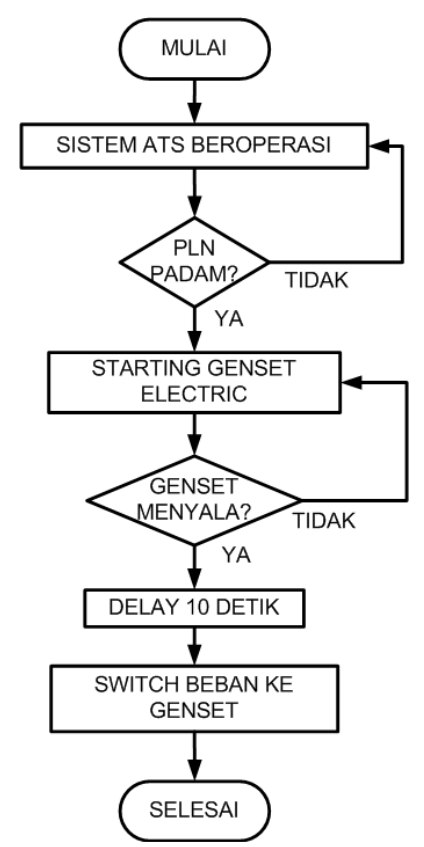

Gambar 7. Diagram alir ATS, saat listrik PLN padam. 
Penjelasan :

Bagian pertama

a. Sistem ATS beroperasi saat sumber dari PLN tengah menyala.

b. Kemudian terjadi pemadaman tiba-tiba oleh PLN. Namun sistem tetap dapat beroperasi karena ada suplai daya cadangan dari UPS.

c. Kemudian, sistem ATS menyalakan Generator Set dengan memicu electric starter pada Genset. Kemudian sistem memeriksa Genset dengan memberikan delay waktu selama 10 detik agar perputaran dan kondisi mesin Generator Set menjadi stabil.

d. Setelah tegangan stabil maka beban akan dipindahkan ke Generator Set yang sebelumnya berada pada PLN.

e. Jika mekanisme berjalan sesuai dengan diagram alir, maka fase saat listrik PLN padam telah selesai.

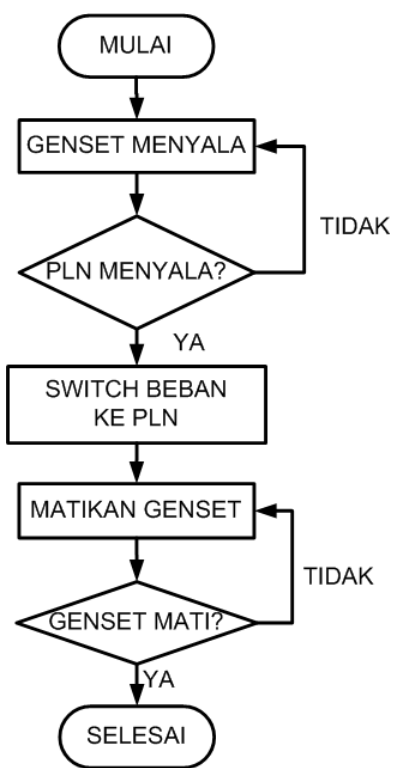

Gambar 8. Diagram alir kondisi saat PLN menyala setelah sebelumnya padam.

\section{Bagian kedua}

a. Mula-mula Generator Set menyala karena sumber utama yaitu dari PLN telah padam beberapa saat sebelumnya.

b. Kemudian sistem ATS mengontrol apakah sumber listrik PLN menyala. Jika ya, maka sistem ATS akan memindahkan kontaktor ke sumber utama yaitu PLN. c. Setelah beban berpindah ke PLN, maka sistem akan segera mematikan Generator Set yang sebelumnya menyala dan menyuplai daya.

d. Jika mekanisme berjalan sesuai diagram, maka fase saat listrik PLN menyala kembali telah selesai.

\section{HASIL DAN PEMBAHASAN}

\section{1. Kanal Masukan}

Kanal masukan merupakan bagian yang digunakan untuk mendeteksi adanya perubahan terhadap sistem yang akan dikendalikan. Dalam penelitian ini, besaran yang menjadi masukan dalam ATS adalah tegangan pada sumber listrik PLN dan genset. Kedua masukan ini yang akan diproses dan menghasilkan respon tertentu sesuai dengan rancangan yang diharapkan dalam sistem ATS ini.

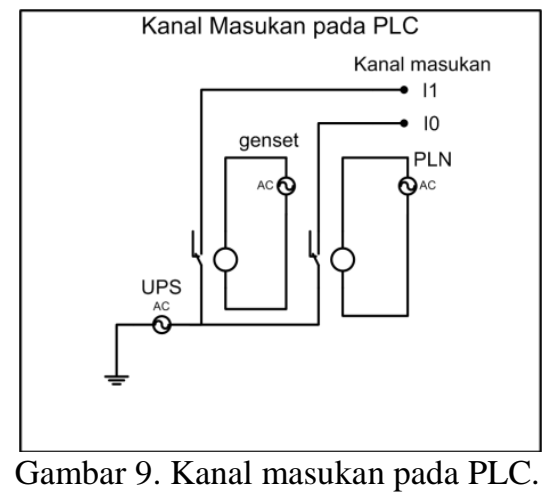

\section{2. Kanal Luaran}

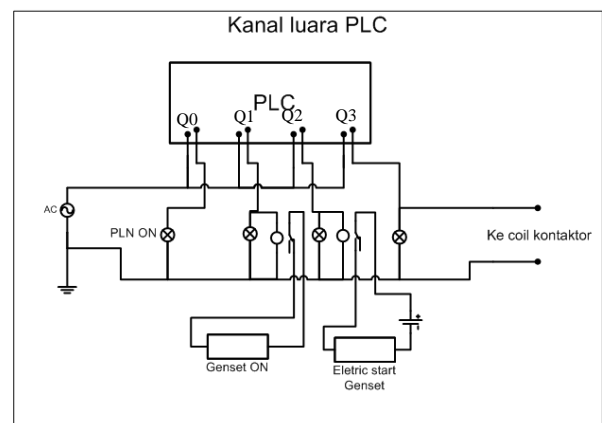

Gambar 10. Konfigurasi kanal luaran PLC.

Kanal luaran PLC yang digunakan sebanyak empat buah. Hasil pengujian dari masing-masing kanal luaran tersebut adalah :

Q0 : akan menyala jika PLN telah menyuplai daya ke beban dan padam jika PLN tidak menyuplai daya ke beban. 
Q1 : akan menyala jika genset berada pada kondisi ON dan padam jika genset berada pada kondisi OFF.

Q2 : akan menyala jika electric starter pada genset menyala dan akan padam jika electric starter pada genset padam.

Q3 : akan menyala jika genset menyuplai daya ke beban dan akan padam jika genset tidak menyuplai daya ke beban.

\section{3. Realisasi perangkat lunak}

ZEN Support Software merupakan program yang digunakan untuk melakukan pemrograman pada PLC. Selain itu, bahasa pemrograman dalam PLC yang digunakan yaitu bahasa ladder diagram yang kemudian ditransfer ke dalam PLC dari komputer menggunakan kabel serial. Ladder diagram yang dibuat menggunakan 12 rung yang terdapat pada PLC yaitu rung 0 hingga 11 .

Dalam penelitian ini, beberapa simbol atau komponen dalam diagram tangga yang digunakan serta waktu tunda yang dirancang agar kerja ATS menyerupai operasional secara manual dijelaskan dalam tabel, yaitu :

Tabel 5. Simbol dan keterangan dalam diagram tangga untuk aplikasi ATS.

\begin{tabular}{|l|l|l|l|}
\hline No & Symbol & Keterangan & Waktu \\
\hline 1 & I0 & Masukan PLC berupa daya dari PLN & 0 \\
\hline 2 & I1 & Masukan PLC berupa daya dari genset & 0 \\
\hline 3 & T0 & Luaran agar genset ON & 0 \\
\hline 4 & T1 & $\begin{array}{l}\text { Trigger untuk menyalakan electric } \\
\text { starter pada genset }\end{array}$ & 5 \\
\hline 5 & T2 & $\begin{array}{l}\text { Trigger untuk melakukan flashing } \\
\text { electric starter pada genset }\end{array}$ & 7 \\
\hline 6 & T3 & $\begin{array}{l}\text { Trigger untuk memutus electric starter } \\
\text { genset }\end{array}$ & 10 \\
\hline 7 & T4 & Trigger switching beban ke genset & 60 \\
\hline 8 & T5 & $\begin{array}{l}\text { Trigger memutus switching beban genset } \\
\text { ke PLN }\end{array}$ & 15 \\
\hline 9 & T6 & Trigger switching beban ke PLN & 0 \\
\hline 10 & T7 & Trigger untuk mematikan genset & 30 \\
\hline 11 & Q0 & Indikator beban ke PLN & 0 \\
\hline 12 & Q1 & $\begin{array}{l}\text { Indikator genset ON atau ON dan } \\
\text { beroperasi }\end{array}$ & \\
\hline 13 & Q2 & $\begin{array}{l}\text { Indikator genset melakukan electric } \\
\text { starting }\end{array}$ & \\
\hline 14 & Q3 & Indikator beban ke genset & \\
\hline
\end{tabular}

\section{Saat PLN Menyala}

Tegangan pada PLN merupakan salah satu masukan pada PLC untuk sistem ATS ini. Ketika PLN menyala, sistem bekerja dengan menghubungkan beban ke sumber listrik utama yaitu PLN. Hal ini ditunjukkan dengan hidupnya lampu pada luaran kanal Q0 PLC. Sehingga kanal Q0 memberikan dua buah informasi yaitu kondisi PLN yang menyala dan beban yang terhubung dengan PLN

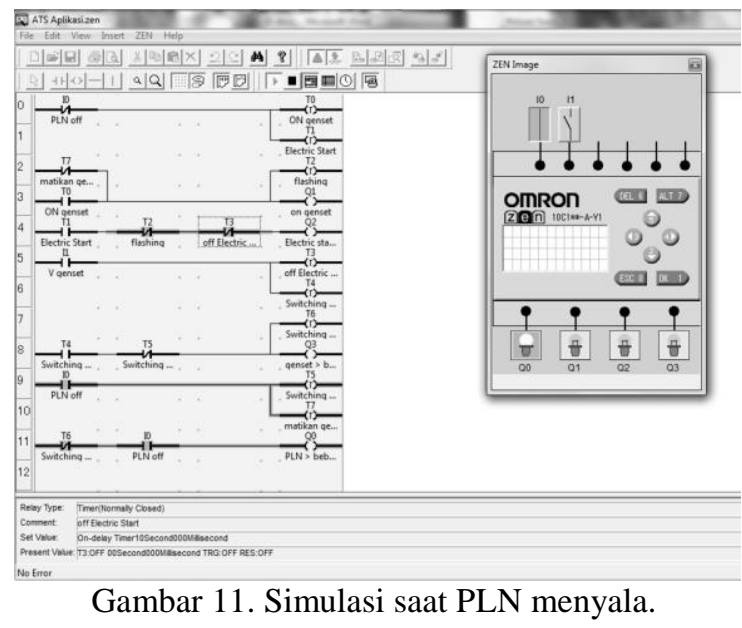

Gambar di atas merupakan kondisi ketika daya dari PLN menyuplai beban. Terlihat bahwa I0 memberikan masukan 1 (terhubung) pada PLC yang kemudian menyebabkan Q0 menyala.

Pada diagram tangga terlihat bahwa I0 terhubung dengan Q0 dan T0. T0 digunakan untuk mengoff-kan genset beberapa saat setelah PLN menyala jika sebelumnya padam. Ketika PLN mengalami pemadaman, kanal I0 memberikan logika 0 kepada PLC. Kemudian masukan ini akan memicu agar genset berada pada kondisi ON dan siap untuk beroperasi ditunjukkan kanal Q1 terhubung. Selain itu, logika 0 pada I0 ini akan memicu Q2 untuk melakukan starting secara electric pada genset. Starting dilakukan dengan menghubungkan dan memutuskan kanal Q2 selama selang waktu 7 detik. Flashing dilakukan oleh T2 setelah T1 terhubung atau memperoleh trigger dari padamnya PLN atau I0.

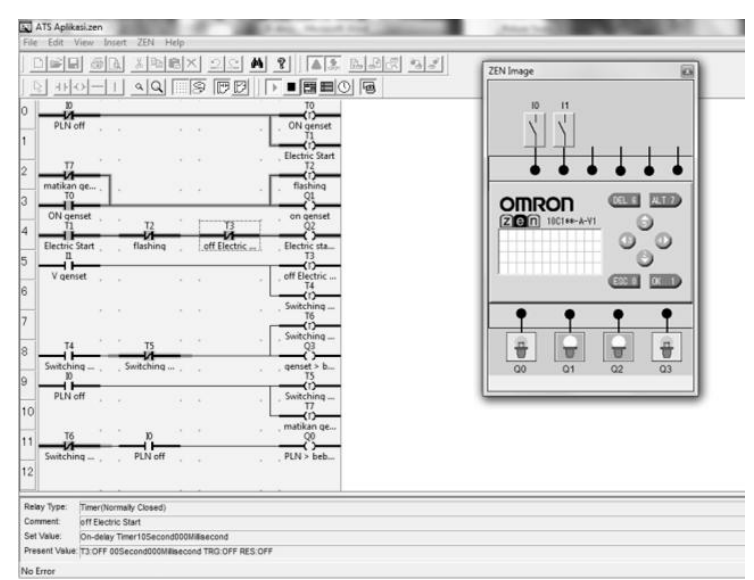

Gambar 12. Simulasi saat genset melakukan electric starter. 
Electric starting pada genset akan dimulai 5 detik setelah genset berada pada kondisi ON. Hal ini ditandai dengan T2 yang mendapat trigger sehingga hubung tertutup. T2 mendapat trigger dari I0 yang ketika PLN padam, maka akan memberi respon agar genset $\mathrm{ON}$ dan genset melakukan electric starter. ON genset diatur oleh T0 sedangkan electric starter diatur oleh T1. T2 berfungsi untuk mematikan electric starter ketika genset sudah menyala.

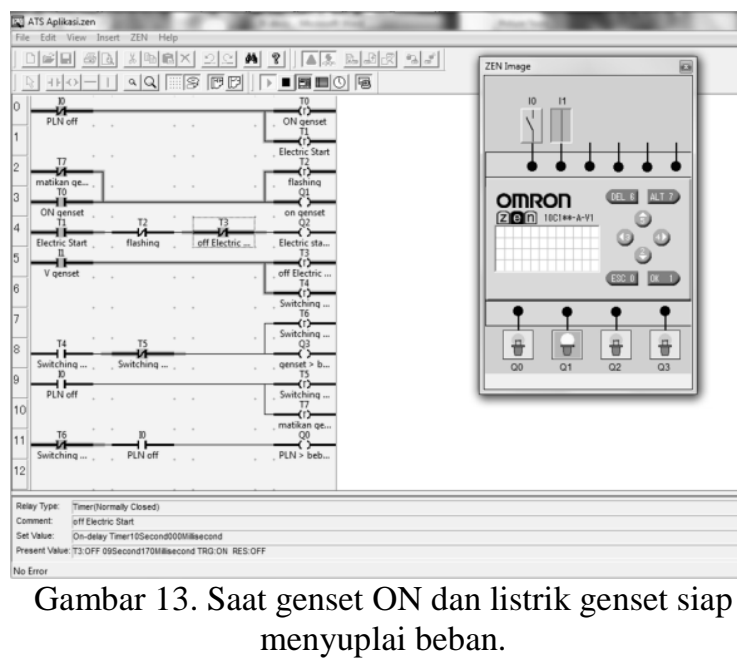

Ketika genset telah menyala, maka genset telah siap menyuplai daya ke beban. Daya dari genset ini kemudian menjadi masukan dari PLC pada ATS. Daya dari genset ini berfungsi untuk mematikan electric starter yang dilakukan oleh kanal luaran Q2. Proses pemutusan electric starter yaitu dengan membuka T3. T3 akan terbuka jika I1 memberikan masukan kepadaATS.

Terhubungnya daya genset dengan beban diatur oleh kanal Q3. Jika lampu pada kanal Q3 menyala, maka daya yang menyuplai beban adalah dari genset.

Ketika genset menyala, genset tidak serta-merta menyuplai daya ke beban. Melainkan menunggu hingga menyala secara stabil. Proses ini diberi waktu selama 60 detik dan diatur oleh T4. T4 akan hubung tertutup ketika telah mendapat masukan dari I1.

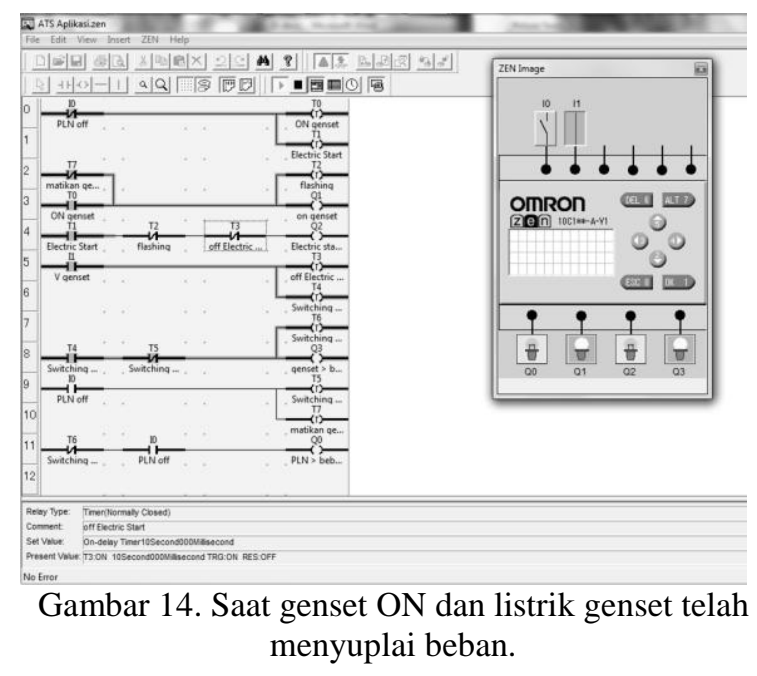

\section{Saat PLN Menyala Setelah Pemadaman}

Sesaat setelah menyala, PLN akan memberikan sinyal 1 pada masukan I0. Masukan ini akan mengakibatkan perpindahan penyuplai daya pada beban, yang semula dari genset digantikan oleh PLN. Proses perpindahan suplai daya ini terjadi sesaat setelah PLN kembali menyala.

Masukan pada I0 ini juga digunakan untuk mematikan genset. Kanal luaran Q1 akan putus dan mengakibatkan genset off. Proses off genset diberikan jeda selama 10 detik.

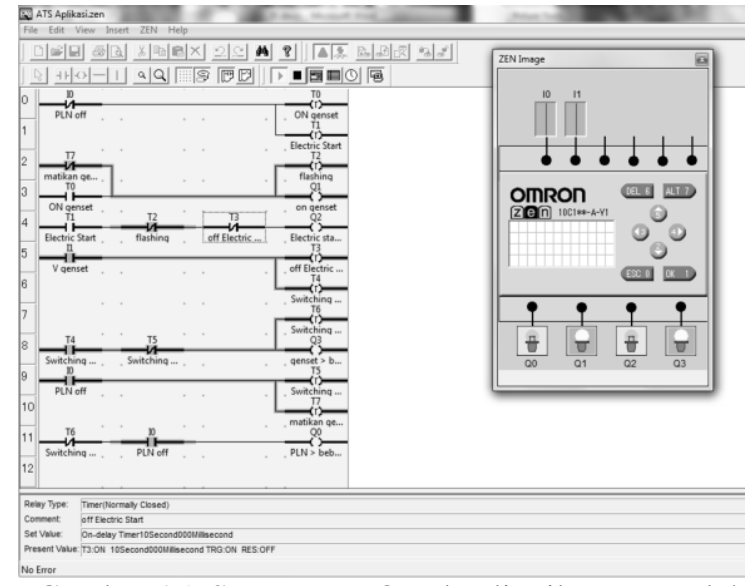

Gambar 15. Saat genset ON dan listrik genset telah menyuplai beban.

Gambar di atas menunjukkan bahwa genset tengah menyuplai daya ke beban namun listrik PLN telah menyala, sebelumnya mengalami pemadaman. Kondisi ini ditunjukkan oleh adanya masukan pada I0 dan I1. Dimana I0 menunjukkan adanya suplai listrik dari PLN dan I1 menunjukkan adanya suplai listrik dari genset.

Berdasarkan pengujian kondisi ini, sistem ATS belum memindahkan beban ke PLN melainkan 
terdapat delay selama 15 detik. Proses ini diatur oleh T5. Ketika PLN dan genset keduanya menyuplai listrik, dibuat sebuah kondisi dimana hanya satu sumber listrik saja yang menyuplai daya ke beban. Hal ini dilakukan untuk mencegah terjadinya gangguan baik pada beban maupun pada penyuplai daya. Karena jika dua buah penyuplai daya bertemu dapat dipastikan kedua sumber akan saling beradu dan dapat merusak sistem kelistrikan.

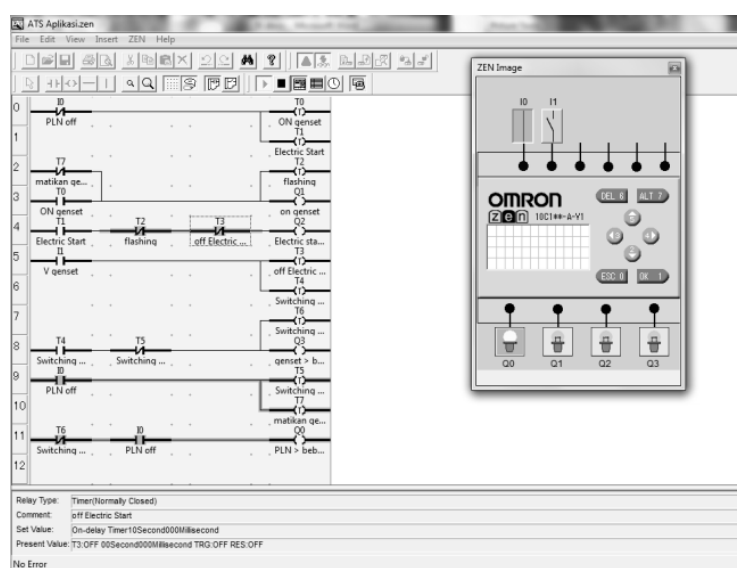

Gambar 16. Simulasi saat genset OFF dan PLN ON, beban disuplai listrik PLN.

Gambar di atas menunjukkan kondisi PLN telah menyala dan listrik pada beban telah disuplai oleh PLN. Pemindahan suplai daya dari genset ke PLN diatur oleh T5. T5 akan memutus suplai daya genset ke beban setelah 15 detik yang kemudian beban disuplai oleh PLN dengan ditandai menyalanya lampu yang terhubung dengan kanal Q0.

Sesaat setelah PLN menyala yang ditunjukkan oleh terhubungnya I0, akan memicu pemindahan suplai daya dari genset ke PLN. Selain itu, masukan dari I0 juga digunakan untuk mematikan genset setelah 30 detik. Proses mematikan genset diatur oleh T7. T6 berfungsi untuk menyalakan Q0 sesaat setelah beban disuplai oleh PLN.

\section{4. Realisasi Perangkat Keras}

Rangkaian implementasi merupakan pengembangan dari rangkaian utama PLC. Rangkaian ini memiliki masukan berupa tegangan PLN dan tegangan genset. Karena masukan ke PLC berupa tegangan dari dua sumber berbeda yaitu PLN dan genset maka kedua sumber tegangan ini hanya memicu relay yang kemudian memberikan masukan pada PLC. Sehingga masukan PLC berasal dari satu sumber listrik saja. Untuk masukan dari PLN digunakan relay R2 dengan kanal masukan pada PLC berupa I0 dan ditunjukkan oleh lampu indikator I0. Kemudian, untuk masukan dari berupa listrik genset digunakan I1 dan ditunjukkan oleh lampu indikator I1.

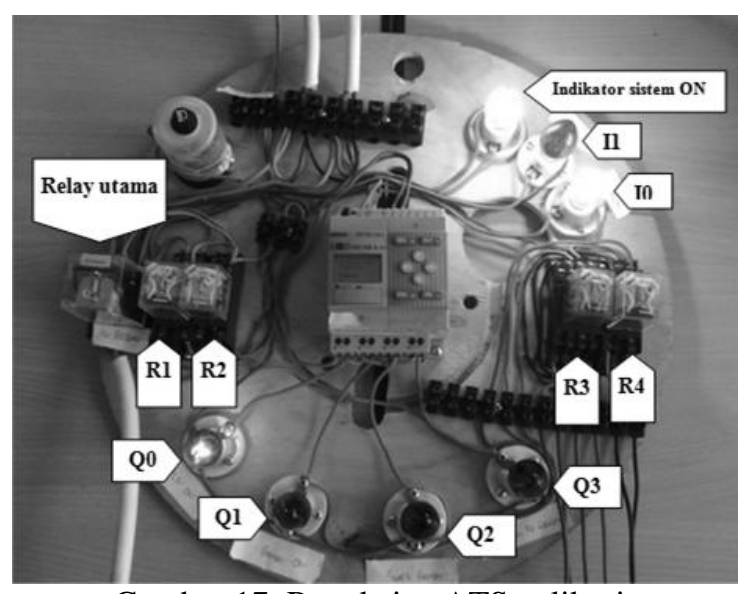

Gambar 17. Rangkaian ATS aplikasi.

\section{5. Pengujian Implementasi Alat}

Proses pengujian dilakukan dengan mengukur waktu respon dari masing-masing bagian. Bagian itu meliputi electric starter on, genset mulai menyala, beban di-switch ke genset, beban diswitch ke PLN dan saat genset mati atau off.

Tabel 6. Data hasil pengujian.

\begin{tabular}{|r|r|r|r|r|r|}
\hline $\begin{array}{l}\text { Data } \\
\text { ke }\end{array}$ & $\begin{array}{l}\text { Electric } \\
\text { starter } \\
\text { on (s) }\end{array}$ & $\begin{array}{l}\text { Genset } \\
\text { menyala } \\
(\mathrm{s})\end{array}$ & $\begin{array}{l}\text { Switching } \\
\text { beban ke } \\
\text { genset (s) }\end{array}$ & $\begin{array}{l}\text { Switching } \\
\text { beban ke } \\
\text { PLN (s) }\end{array}$ & $\begin{array}{l}\text { Genset } \\
\text { OFF (s) }\end{array}$ \\
\hline Target & 5 & - & 60 & 15 & 30 \\
\hline 1 & 5,38 & 8 & 59,62 & 15,24 & 29,77 \\
\hline 2 & 5,71 & 7,64 & 59,85 & 15,41 & 30,61 \\
\hline 3 & 5,23 & 6,82 & 60,71 & 15,15 & 29,43 \\
\hline 4 & 5,86 & 7,72 & 60,02 & 15,16 & 30,21 \\
\hline 5 & 5,3 & 6,94 & 59,82 & 15,16 & 30,37 \\
\hline 6 & 5,45 & 6,78 & 60,02 & 15,26 & 30,42 \\
\hline 7 & 5,37 & 6,59 & 60,21 & 15,37 & 30,58 \\
\hline 8 & 5,54 & 6,93 & 60,56 & 15,17 & 29,41 \\
\hline 9 & 5,54 & 6,81 & 60,34 & 15,03 & 30,02 \\
\hline 10 & 5,37 & 6,5 & 60,17 & 15,18 & 30,24 \\
\hline
\end{tabular}

Untuk menghitung persentase kesalahan dari sistem ATS ini, dapat menggunakan rumus :

$$
\text { \%error }=\frac{\left|x_{n-} x_{0}\right|}{x_{0}} 100 \%
$$

dimana :

$x_{n}=$ data ke $\mathrm{n}$

$x_{0}=$ data awal (rancangan sistem) 
Berdasarkan rumus di atas, diperoleh hasil perhitungan untuk masing-masing data sebagai berikut :

Tabel 7. Persentase kesalahan bagian sistem ATS

\begin{tabular}{|r|r|r|r|r|}
\hline $\begin{array}{l}\text { Data } \\
\text { ke }\end{array}$ & $\begin{array}{l}\text { Electric } \\
\text { starter } \\
\text { on (\%) }\end{array}$ & $\begin{array}{l}\text { Switching } \\
\text { beban ke } \\
\text { genset (\%) }\end{array}$ & $\begin{array}{l}\text { Switching } \\
\text { beban ke } \\
\text { PLN (\%) }\end{array}$ & $\begin{array}{l}\text { Genset } \\
\text { OFF } \\
(\%)\end{array}$ \\
\hline 1 & 7,6 & 7,6 & 4,8 & 4,6 \\
\hline 2 & 14,2 & 3 & 8,2 & 12,2 \\
\hline 3 & 4,6 & 14,2 & 3 & 11,4 \\
\hline 4 & 17,2 & 0,4 & 3,2 & 4,2 \\
\hline 5 & 6 & 3,6 & 3,2 & 7,4 \\
\hline 6 & 9 & 0,4 & 5,2 & 8,4 \\
\hline 7 & 7,4 & 4,2 & 7,4 & 11,6 \\
\hline 8 & 10,8 & 11,2 & 3,4 & 11,8 \\
\hline 9 & 10,8 & 6,8 & 0,6 & 0,4 \\
\hline 10 & 7,4 & 3,4 & 3,6 & 4,8 \\
\hline rerata & 9,5 & 5,48 & 4,26 & 7,68 \\
\hline
\end{tabular}

Nilai rerata kesalahan sistem ATS yaitu :

$$
\frac{9,5+5,48+4,26+7,68}{4}=6,73 \%
$$

ATS yang dirancang ini memiliki persen kesalahan yang lebih besar dari kelompok keempat yaitu kelompok yang tidak begitu memperhatikan presisi dan ketelitian. Hanya pada switching beban ke PLN yang memiliki persen kesalahan di bawah 5\% yaitu 4,26\% dan termasuk dalam kelompok alat yang tidak begitu memperhatikan presisi dan ketelitian. Sehingga dapat dikatakan bahwa sistem ATS hasil rancangan ini tergolong ke dalam rancangan yang tidak begitu memperhatikan presisi dan ketelitian. Sedangkan untuk persen kesalahan sistem diperoleh nilai $6,73 \%$ dan merupakan lebih besar dari kelompok alat yang tidak begitu memperhatikan presisi dan ketelitian. Untuk itu, perlu adanya penelitian lanjutan yang dapat memperkecil nilai persen kesalahan. Sehingga akurasi sistem ATS dapat lebih baik.

Ketika pengujian berlangsung, terjadi beberapa kondisi di lapangan yang perlu dicermati dan menjadi perhatian. Diantaranya adalah genset harus berada pada kondisi optimal dan normal. Tidak dalam keadaan mengalami kerusakan atau kendala. Misalnya pada bagian electric starternya harus siap digunakan. Komponen dari electric starter ini yang utama misalnya adalah baterai. Jika baterai dalam kondisi baik, maka electric starter dapat digunakan dan sistem dapat bekerja seperti rancangan. Namun jika baterai tidak berada pada kondisi baik, maka electric starter tidak dapat digunakan. Akibatnya sistem tidak dapat berjalan sempurnya atau mengalami kegagalan.

IV.

\section{SIMPULAN DAN SARAN}

\subsection{Simpulan}

Berdasarkan data hasil pengujian alat dan pembahasan mengenai data hasil uji alat, dapat ditarik kesimpulan:

1. Sistem ATS yang dibangun berhasil beroperasi dengan baik sesuai spesifikasi yang diinginkan.

2. Dari keempat bagian sistem, hanya pada bagian switching beban ke PLN yang memiliki persen kesalahan di bawah 5\%, yaitu $4,26 \%$ yang tergolong ke dalam alat yang tidak begitu memperhatikan presisi dan ketelitian.

3. Sedangkan untuk persen kesalahan sistem secara keseluruhan setelah dirata-ratakan sebesar 6,73\% dan lebih besar dari kelompok alat yang tidak begitu memperhatikan presisi dan ketelitian.

\subsection{Saran}

1. Perlu adanya pengecekan berkala kondisi genset terutama bagian electric starter agar siap beroperasi saat dibutuhkan.

2. Perlu adanya penelitian lebih lanjut untuk implementasi ATS yang mampu mematikan sistem saat di luar jam kantor.

\section{DAFTAR PUSTAKA}

[1] Anonymous, 2003, Zen Support Software Operation Manual, Omron,Jepang.

[2] Atmojo, B. T., 2013. Model Sistem Kendali Pintu Otomatis Menggunakan Barcode Berbasis PC (Personal Computer) pada Gerbang Laboratorium Teknik Elektro UNILA. Skripsi, Teknik Elektro Universitas Lampung. Bandar Lampung.

[3] Purwanto, N. D., 2011, Rancang Bangun Pengaturan Bahan Bakar Pada Genset Hybrid (Bensin Dan Bioetanol) Untuk Aplikasi Automatic Transfer Switch (Ats) Pada Listrik Rumah Tangga, Skripsi, Teknik 
Elektro Universitas Lampung. Bandar Lampung.

[4] Waluyanti, S., 2008, Alat Ukur Dan Teknik Pengukuran Jilid 1, Departemen Pendidikan Nasional, Jakarta.

[5] Yudamson, A., 2011, Rancang Bangun Model Lift Cerdas 3 Lantai Dengan Menggunakan PLC Omron ZEN 20C1AR-
A-V2, Skripsi, Teknik Elektro Universitas Lampung. Bandar Lampung.

[6] Wahyudi, Pengendalian mesin Hoist Hanger dalam Proses PTC/ED

Menggunakan PLC Omron, Jurnal,

Universitas Diponegoro, 2009, Hal. 25-26,

Tanggal diakses pada 28 Januari 2013,

http://eprints.undip.ac.id/20176/1/WAHYU

DI.pdf. 